\title{
Correction to: Anti-inflammatory and antioxidant effects of 2, 7-dihydroxy-4, 6-dimethoxy phenanthrene isolated from Dioscorea batatas Decne
}

\author{
Ji Sun Lim" ${ }^{1 \dagger}$, Dongyup Hahn ${ }^{1 \dagger}$, Myeong Ju Gu${ }^{1}$, Jisun Oh${ }^{1}$, Jeong Soon Lee ${ }^{2}$ and Jong-Sang Kim ${ }^{{ }^{*}}$
}

\section{Correction to: Appl Biol Chem (2019) 62:29}

https://doi.org/10.1186/s13765-019-0436-2

After the publication of the article [1], it was found that the Received and Accepted dates were missing inadvertently in the originally published version.

The History dates are shown below.

Received: 13 Apr 2019

Accepted: 03 May 2019

"The original article has been corrected."

\section{Reference}

1. Lim JS, Hahn D, Gu MJ, Oh J, Lee JS, Kim J-S (2019) Anti-inflammatory and antioxidant effects of 2, 7-dihydroxy-4, 6-dimethoxy phenanthrene isolated from Dioscorea batatas Decne. Appl Biol Chem 62:29. https://doi. org/10.1186/s13765-019-0436-2

\section{Publisher's Note}

Springer Nature remains neutral with regard to jurisdictional claims in published maps and institutional affiliations.

\section{Author details}

'School of Food Science and Biotechnology, Kyungpook National University, Daegu 41566, South Korea. ${ }^{2}$ Forest Resources Development Institute of Gyeongsangbuk-do, Andong 36605, South Korea.

The original article can be found online at https://doi.org/10.1186/s1376 5-019-0436-2.

Published online: 06 July 2019

\footnotetext{
*Correspondence: vision@knu.ac.kr

${ }^{\dagger} \mathrm{Ji}$ Sun Lim and Dongyup Hahn have equally contributed to this paper as

first authors

${ }^{1}$ School of Food Science and Biotechnology, Kyungpook National

University, Daegu 41566, South Korea

Full list of author information is available at the end of the article
} provided you give appropriate credit to the original author(s) and the source, provide a link to the Creative Commons license, and indicate if changes were made. 